\title{
PAPER
}

\section{Normal jugular bulb oxygen saturation}

\section{A Chieregato, F Calzolari, G Trasforini, L Targa, N Latronico}

J Neurol Neurosurg Psychiatry 2003;74:784-786

See end of article for authors' affiliations

..................

Correspondence to: Dr A Chieregato, Via Boccacanale S. Stefano no. 25, 44100 Ferrara Italy;

achiere@ausl-cesena.emr.it

Received 31 May 2002 In revised form 9 October 2002

Accepted

2 December 2002
Background: Normal values of the jugular bulb oxygen saturation were obtained in 1942 and in 1963. Correct catheter positioning was not confirmed radiologically.

Objectives: To replicate the measurements during angiographic catheterisation of the jugular bulb.

Methods: Oxygen saturation in the jugular bulb $\left(\mathrm{SiO}_{2}\right)$, inferior petrosal sinus $\left(\mathrm{Sips}_{2}\right)$, and internal jugular vein was bilaterally measured in 12 patients with Cushing's syndrome undergoing selective bilateral catheterisation of the inferior petrosal sinus. In addition, data from the two old series were reanalysed for comparison.

Results: $\mathrm{SjO}_{2}$ values $(44.7 \%)$ were significantly lower than in the two old series, particularly concerning the normal lower limit (54.6\% and 55.0\% respectively). Comparative analysis suggests that contamination with the extracerebral blood of the facial veins and inferior petrosal sinuses was responsible for falsely high $\mathrm{SjO}_{2}$ values in the two old series.

Conclusions: The normal lower $\mathrm{SjO}_{2}$ limit is lower than previously recognised. This may have practical implications for treating severe head trauma patients.
M onitoring of jugular bulb vascular oxygen saturation $\left(\mathrm{SjO}_{2}\right)$ is currently suggested in patients with severe head trauma as a global measure of the adequacy of the cerebral blood flow (CBF) to brain metabolic requirements. ${ }^{1} \mathrm{SjO}_{2}$ in normal volunteers was first obtained by Gibbs et al in 1942, ${ }^{2}$ and then by Datsur et al in 1963. In 1945 Gibbs et al also showed that the $\mathrm{SjO}_{2}$ does not differ in simultaneous sampling of both right and left jugular bulbs. ${ }^{4}$ However, these physiological data were obtained by direct puncture of the jugular veins without radiological confirmation of the needle's or catheter's tip position.

Substantial extracerebral contamination with high oxygen saturation values may occur if the blood is withdrawn from the facial vein, joining a few centimetres below the jugular bulb and possibly from the inferior petrosal sinus, joining immediately below the jugular bulb. Contamination may also occur if the catheter is correctly positioned and blood withdrawal is too fast. Therefore, extracerebral blood contamination could have occurred in the two old series, and falsely high oxygen saturation values could have been obtained.

We sought to replicate the $\mathrm{SjO}_{2}$ measurements during angiographic catheterisation of the jugular bulb.

\section{MATERIALS AND METHODS}

The study was approved by the local review board, and written informed consent was obtained by the patients. The study was carried out on 12 patients (nine females; median age 39 years, range 25-72) with Cushing's syndrome, whose aetiology had to be defined. Selective bilateral venous sampling in the inferior petrosal sinus was necessary to distinguish those individuals with microadenoma of the pituitary from some paraendocrine tumours (for example, carcinoids or phaeochromocytoma) that ectopically produce corticotrophin releasing hormone (CRH) or adrenocorticotrophin hormone (ACTH). We took advantage of this procedure, which was done using a digital subtraction angiography system, to obtain multiple bilateral samples from: (1) internal jugular veins at the level of the 5 th cervical vertebra (midlevel) $\left(\mathrm{SmidjO}_{2}\right) ;(2)$ inferior petrosal sinuses $\left(\mathrm{SipsO}_{2}\right)$; and (3) dome of internal jugular vein bulbs $\left(\mathrm{SjO}_{2}\right)$. Correct position of the tip of the catheter was meticulously checked under direct angiographic observation with contrast medium injection. Blood was withdrawn slowly ( $1 \mathrm{ml}$ per minute $)^{6}$ and venous blood was analysed for oxygen saturation with a co-oximeter (IL 482, CO-Oximeter, Instrumentation Laboratory, Milan, Italy).

Patients were excluded if they had abnormal arterial oxygen saturation $(<97 \%$ in room air), anaemia of recent onset ( $\mathrm{Hb}$ less than $100 \mathrm{~g} / \mathrm{l}$ in the past 10 days), or haemodynamic instability. Chronic arterial hypertension is associated with an adaptation of $\mathrm{CBF}$, and metabolic coupling is ultimately affected only by severe involvement of the cerebral vascular circulation. ${ }^{37}$ Therefore, stable hypertension was not an exclusion criterion. Conversely, patients with hypertension of recent onset or with poorly controlled hypertension were excluded. Patients were also excluded if they had evidence of acute or chronic diseases affecting the central nervous system (CNS) other than microadenoma of the pituitary, or if they had hyperventilation (more than 25 breaths per minute for at least one minute) during the procedure.

Pain and agitation were carefully avoided because they could induce ACTH secretion and cerebral metabolic rate of oxygen $\left(\mathrm{CMRO}_{2}\right) / \mathrm{CBF}$ changes, both of which were undesirable. The procedure was carried out in a noise free environment, and accurate local anaesthesia was performed before venous cannulation. Arterial blood pressure was measured at five minute intervals by using an automated device with cuff inflation. Arterial oxygen saturation $\left(\mathrm{SaO}_{2}\right)$ was continuously monitored using a pulse oximeter.

\section{Statistical analysis}

$\mathrm{SjO}_{2}$ values are presented as mean, upper (mean plus 2 standard deviations (SD)), and lower (mean minus 2 SD) limit. Precision of each point estimate was evaluated by $95 \%$ confidence intervals (95\% CI). ${ }^{8}$ Comparison of the venous oxygen saturation in the jugular bulbs, inferior petrosal sinuses, and midlevel jugular veins was done using analysis of variance (ANOVA).

$\mathrm{SjO}_{2}$ values from this series were compared to those from the two historical series by Gibbs and colleagues ( 50 healthy

Abbreviations: $\mathrm{ACTH}$, adrenocorticotrophin hormone; ANOVA analysis of variance; $\mathrm{CBF}$, cerebral blood flow; $\mathrm{CMRO}_{2}$, cerebral metabolic rate of oxygen; CNS, central nervous system; $\mathrm{CRH}$, corticotrophin releasing hormone; $\mathrm{SiO}_{2}$, jugular bulb oxygen saturation; $\mathrm{Sips}_{2}$, inferior petrosal sinus oxygen saturation 


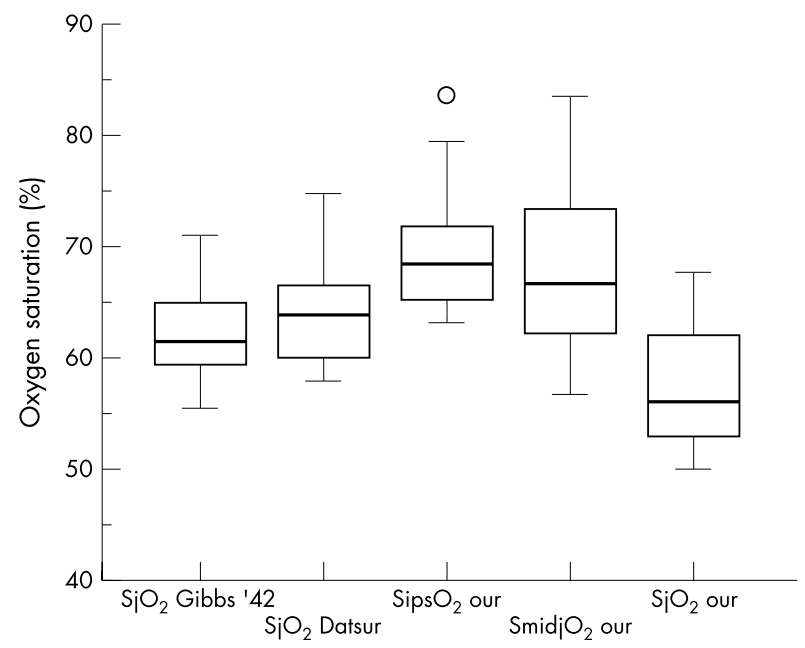

Figure 1 Oxygen saturation in the jugular bulb $\left(\mathrm{SjO}_{2}\right)$ in the series by Gibbs (1942) and Datsur, and in the inferior petrosal sinus $\left(\mathrm{Sips}_{2}\right)$, midlevel jugular vein $\left(\mathrm{Smidj}_{2}\right)$, and jugular bulb in the present series.

young volunteers $)^{2}$ and Datsur and colleagues (26 healthy elderly volunteers ). ${ }^{3}$ Data from the three series were compared by means of ANOVA.

Analysis of differences between right and left $\mathrm{SjO}_{2}$ in simultaneous samples was done using paired Student's $t$ test. In addition, the degree of agreement was evaluated according to Bland and Altman. ${ }^{9}$ The same procedure was applied to the data published in 1945 by Gibbs et al, in which bilateral measurements were performed in 25 patients with various psychiatric disorders. ${ }^{2}$ As suggested by the authors, seven patients were excluded because of data inconsistency.

In all cases two tailed tests were used and $\mathrm{p}<0.05$ was chosen to define statistically significant differences. Box plots were used for graphic presentation.

\section{RESULTS}

$\mathrm{SaO}_{2}$ and arterial blood pressure remained stable during the procedure. In two patients simultaneous catheterisation of jugular bulbs was not possible because of severe ear pain, in one the procedure was interrupted due to a contrast medium anaphylactic reaction, and one had hyperventilation after CRH administration. Overall, 143 measurements were made in 12 patients. Haemoglobin was 130 g/l (SD 22).

Oxygen saturation was significantly lower in samples from the jugular bulb compared to inferior petrosal sinus and midlevel jugular vein samples $(\mathrm{F}=8.445 \mathrm{l}, \mathrm{p}=0.0014)$. Interestingly, the $\mathrm{SjO}_{2}$ values in the series by Gibbs and Datsur were intermediate between $\mathrm{SjO}_{2}$ and $\mathrm{SipsO}_{2}-\mathrm{SmidjO}_{2}$ in the present series (fig l).

$\mathrm{SjO}_{2}$ values in the present series were significantly lower than in the two series by Gibbs and Datsur $(\mathrm{F}=9.4998$, $\mathrm{p}=0.0002$ ). Table 1 presents mean values, upper and lower limits, and $95 \%$ CI.
Differences between right and left $\mathrm{SjO}_{2}$ in simultaneous samples were not statistically significant, neither in the present series $(t=0.1978$, two tailed $\mathrm{p}=0.8481)$ nor in the Gibbs series $(t=-0.1464$, two tailed $\mathrm{p}=0.8846)$; however, limits of agreement were wider in the latter. Results, expressed as mean difference (95\% CI), and upper (95\% CI) and lower (95\% CI) limits of agreement were as follows: present study: $0.2 \%(-1.2$ to 1.7$) ; 3.7 \%$ ( 1.2 to 6.3$) ;-3.3 \%$ ( -5.8 to -0.7$)$; Gibbs: $-0.1 \%$ ( -1.3 to 1.1$)$; $6.5 \%$ (4.4 to 8.6$) ;-6.7 \%$ ( -8.8 to $-4.6)$.

\section{DISCUSSION}

We found significantly lower $\mathrm{SjO}_{2}$ values in this series $(44.7 \%)$ than reported in two old series $(54.6 \%, 55.0 \%)$, the only ones in which $\mathrm{SjO}_{2}$ was measured in normal volunteers. The difference was not accounted for by the fact that patients in the present series had Cushing's syndrome. In fact, all patients had a syndrome of recent onset, whose pathogenesis, whether due to microadenoma of the pituitary or paraendocrine tumours, had yet to be defined. In addition, patients with severe unstable hypertension, in whom uncoupling of CBF and $\mathrm{CMRO}_{2}$ may occur, were excluded.

Three facts are relevant to explain our results. First, we used a digital angiography system and vascular catheters were exactly positioned in the dome of the jugular bulb. In the Gibbs and Datsur series the catheter positioning in the jugular bulb was blind, and cervical $x$ ray confirmation of the final catheter position was not performed. Therefore, extracerebral blood contamination from the facial veins, ${ }^{10}$ and as shown in this study, from the inferior petrosal sinuses may have occurred in some patients. Our results support this hypothesis showing that the $\mathrm{SjO}_{2}$ values in the old series were intermediate between $\mathrm{SjO}_{2}$ and $\mathrm{SipsO}_{2}-\mathrm{SmidjO}_{2}$ (extracerebral) in the present series. Second, blood samples in our study were withdrawn slowly, a factor that has been showed to avoid extracerebral blood contamination, provided that the catheter is correctly positioned in the jugular bulb. ${ }^{6}$ Third, we measured haemoglobin oxygen saturation by mean of a co-oximeter, the reference method based on three wavelength spectrophotometry, ${ }^{11}$ while Datsur et al used a two wavelength spectrophotometric method, ${ }^{12}$ and Gibbs et al the Van Slyke manometric method. ${ }^{13}$ The two latter methods overestimate oxygen saturation compared with the co-oximeter, particularly for the lower range of oxygen saturation, as is the case in venous samples. ${ }^{11}$

\section{Normal $\mathrm{SiO}_{2}$ limit lower than previously recognised: does it matter?}

$\mathrm{SjO}_{2}$ values below the lower normal limit have been defined as jugular desaturation - that is, situations of critical inadequacy of $\mathrm{CBF}$ to $\mathrm{CMRO}_{2}$, "from norms defined by Gibbs and coworkers", ${ }^{14}$ and have been proven in a single study to independently affect the outcome of severe head trauma. ${ }^{15}$ However, the methods on how to summarise insult data such as jugular desaturation have only recently been defined, ${ }^{16}$ while in previous studies the jugular desaturation was simply dichotomised as present or absent, based on Gibbs' data. Therefore, a new limit could modify the result. More

Table 1 Oxygen saturation values in the jugular bulb $\left(\mathrm{SjO}_{2}\right)$

\begin{tabular}{llll}
\hline & $\mathrm{SiO}_{2}$ & & \\
\cline { 2 - 4 } & Mean $(95 \% \mathrm{Cl})$ & Upper limit $(95 \% \mathrm{Cl})$ & Lower limit (95\% CI) \\
\hline Present series & $57.1(52.3$ to 61.6$)$ & $69.5(61.2$ to 77.7$)$ & $44.7(36.5$ to 53.0$)$ \\
Gibbs (1942) & $62.0(61.0$ to 63.1$)$ & $69.4(67.6$ to 71.2$)$ & $54.6(52.8$ to 56.5$)$ \\
Datsur (1963) & $64.3(62.4$ to 66.2) & $73.7(70.4$ to 76.9$)$ & $55.0(51.7$ to 58.2$)$ \\
\hline
\end{tabular}


importantly, it is suggested that jugular desaturations, variously defined as $\mathrm{SjO}_{2}$ less than $50 \%$ or $54 \%,{ }^{1}$ are treated aggressively, although benefits are unproven. A new normal limit further weakens the legitimacy of such treatments.

This study included a small sample of patients and therefore conclusions should be taken cautiously. Due to the lack of invasiveness that can be attributed to the method itself, our results can be easily replicated. If the normal lower $\mathrm{SjO}_{2}$ limit is confirmed to be as low as $46 \%$, redefinition of "normality" applied to $\mathrm{SjO}_{2}$ may have diagnostic, prognostic, and therapeutic implications.

\section{Authors' affiliations}

A Chieregato, L Targa, Department of Anesthesiology-Intensive Care, Section of Neurocritical Care, Ospedale Civile M. Bufalini, Cesena, Italy F Calzolari, Department of Neuroradiology, Arcispedale S. Anna, Ferrara, Italy

G Trasforini, Department of Clinical Endocrinology, University of Ferrara, Italy

N Latronico, Institute of Anesthesiology-Intensive Care, University of Brescia, Italy

Competing interests: none declared

\section{REFERENCES}

1 Macmillan CSA, Andrews PJD. Cerebrovenous oxygen saturation monitoring: practical considerations and clinical relevance. Intensive Care Med 2000;26:1028-36

2 Gibbs EL, Lennox WG, Nims LF, et al. Arterial and cerebral venous blood. Arterial-venous differences in man. J Biol Chem

$1942 ; 144: 325-32$
3 Datsur DK, Lane MH, Hansen DB, et al. Effects of aging on cerebral circulation and metabolism in man. In: Birren JE, Butler RN, Greenhouse $\mathrm{SW}$, et al, eds. Human aging. A Biological and behavioral study. Washington, DC: US Government Printing Office, 1963:59-76.

4 Gibbs EL, Lenox WG, Gibbs FA. Bilateral internal jugular blood. Comparison of $\mathrm{AV}$ differences, oxygen-dextrose ratios and respiratory quotients. Am J Psychiatry 1945;102: 184-90.

5 Miller DL, Doppman JL. Petrosal sinus sampling: technique and rationale. Radiology 1991;178:37-47.

6 Matta BF, Lam AM. The rate of blood withdrawal affects the accuracy of jugular venous bulb. Oxygen saturation measurements. Anesthesiology 1997:86:806-8.

7 Aaaslid R, Lindegaard KF, Sorteberg W, et al. Cerebral autoregulation dynamics in humans. Stroke 1989;20:45-52.

8 Altman DG. Principles of statistical analysis. In: Practical statistics for medical research. Boca Raton, FL: Chapman \& Hall, 1991:152-78.

9 Bland JM, Altman DG. Statistical methods for assessing agreement between two methods of clinical measurement. Lancet 1986;ii:307-10.

10 Lassen NA, Lane MH. Validity of internal jugular blood for study of cerebral blood flow and metabolism. J Appl Physiol 1961;16:313-20.

11 Maas AHJ, Hamelink ML, De Leeuw RJM. An evaluation of the spectrophotometric determination of $\mathrm{HbO}_{2}, \mathrm{HbCO}$ and $\mathrm{Hb}$ in blood with the CO-Oximeter IL 182. Clin Chim Acta 1970;29:303-9.

12 Deibler GE, Holmes MS, Campbell PL, et al. Use of triton X-100 as a haemolytic agent in the spectrophotometric measurement of blood $\mathrm{O}_{2}$ saturation. J Appl Physiol 1959;14:133-6.

13 Van Slyke DD, Neill JM. The determination of gases in blood and other solutions by vacuum extraction and manometric measurement. I. J Biol Chem 1924;61:523-73.

14 Cruz J, Miner ME, Allen SJ, et al. Continuous monitoring of cerebral oxygenation in acute brain injury: injection of mannitol during hyperventilation. J Neurosurg 1990;73:725-30.

15 Gopinath SP, Robertson CS, Contant CF, et al. Jugular venous desaturation and outcome after head injury. I Neurol Neurosurg Psychiatry 1994;57:717-23.

16 Signorini DF, Andrews PJ, Jones PA, et al. Adding insult to injury: the prognostic value of early secondary insults for survival after traumatic brain injury. J Neurol Neurosurg Psychiatry 1999;66:26-31. 


\author{
Sir David Ferrier MD, FRS
}

$\overbrace{}^{a}$ arpenter ranked Ferrier's cerebral localisation among the greatest advances in the physiology of the nervous system made in the past 50 years. ${ }^{1}$ It formed a direct link between Jackson and Sherrington, with both of whom he had worked.

Born in Aberdeen, Ferrier studied there under Alexander Bain, on whose advice in 1864 he visited Heidelberg, to study psychology with Helmholtz and Wundt. Wundt had just (1862) completed the Beiträge zur theorie der sinneswahrnehmung that contained the first statement of his "physiological psychology". Ferrier completed his medical training at Edinburgh where Thomas Laycock, ${ }^{2-3}$ inclined him towards neurology.

He worked in London from 1880, and was appointed Professor of Neuropathology, King's College Hospital, in 1889. But his major research began earlier at The West Riding Lunatic Asylum, Wakefield. There he showed that stimulation of the cerebral cortex could produce movements and fits, and that cerebral functions were localised in definable discrete areas.

Before him, in 1866, Friedrich Albert Lange (1828-75) had distinguished between localisation of function and localisation of symptoms. Broca, Bouillaud, ${ }^{4}$ Flourens, ${ }^{5}$ and others had tried to relate behaviour, language, and disease to different areas of the brain, but Franz Joseph Gall's (1758-1828) phrenology was still accepted by many. ${ }^{6}$ Influenced by Bain and Spencer, Ferrier ${ }^{7-8}$ tested Hughlings Jackson's notion that motor and sensory functions must be represented in an organised fashion in the cortex. Gustav Theodor Fritsch and Eduard Hitzig in 1870, using galvanic stimulation of the cerebrum in the dog', had recently shown that circumscribed cortical areas control movements of the contralateral limbs and that ablation of these areas caused weakness in these limbs. Their findings established electrophysiology as an experimental tool and showed the localisation of motor function in the hemispheres.

Ferrier used faradic rather than galvanic current to elicit movements that resembled primate walking, grasping, scratching, and thereby confirmed and extended the results of Fritsch and Hitzig. Ferrier localised smell in the uncus of the temporal lobe; hearing in the superior temporosphenoidal convolution; and primate vision in the angular gyrus, although this was later corrected by Munk's discovery of the occipital visual cortex. Ferrier used both ablation and electrical stimulation to produce topography of localisation of function in several species.
Removal of the precentral gyrus, he found, caused paralysis and a hemiplegic position of the contralateral limbs. In 1876 he collected his results to produce his acclaimed The functions of the brain..$^{10}$ This demonstrated that ablations and faradic stimulation of the brain were better than the galvanic techniques of Fritsch and Hitzig. He had thereby mapped sensory and motor areas across several species, thus expanding both understanding ${ }^{11}$ and localisation of motor and sensory functions. ${ }^{12-14}$

Ferrier also performed decerebration experiments to distinguish between voluntary and reflex movement, and examined the control of eye movements by electrical stimulation of the cerebellum. He was not obsessed by the anatomical localisation. The functions of the cerebrum were sensorimotor:

"From the complexity of mental phenomena and the participation in them of both motor and sensory substrata, any system of localization of mental faculties which does not take both factors into account must be radically false." He thus anticipated 20th century holistic concepts of cerebral function.

"Ferrier was more than an experimenter; he was, rather, a philosopher who did not philosophise but who experimented," remarks Rioch. ${ }^{15}$

By making lesions in the anterior frontal cortex, he deduced the effect on function: "while not actually deprived of intelligence . . they had lost the faculty of attentive and intelligent observation."

Thus, the frontal lobes might subserve the function of selection and inhibition of competing ideas.

He dedicated his work to Jackson:

"To Dr Hughlings Jackson who from a clinical and pathological standpoint anticipated many of the more important results of recent experimental investigation into the functions of the cerebral hemispheres, this work is dedicated as a mark of the author's esteem and admiration." Ferrier The functions of the brain (1876).

Jackson, similarly, had been inspired by Spencer and frequently cited his writings. Sherrington, in turn, dedicated his lectures on The integrative action of the nervous system (1906) to Ferrier. And in his obituary notice of Ferrier for the Royal Society, ${ }^{16}$ Sherrington remarked:

"Ferrier has done the most important research in proving cerebral localization, in placing it at the centre of neurological interest, and in providing the basis for a "scientific phrenology"'". ${ }^{11}$

He continued his clinical work applying these experimental findings to patients, and encouraging surgeons to operate on intracranial lesions; thus, Rickman Godlee said he was a powerful force in initiating brain surgery.

Among many honours, he received an Hon DSc, University of Cambridge, in 1914 and in 1911 a Knighthood. He was elected FRS in 1876, FRCP in 1877, and Goulstonian Lecturer in 1878 . Not least of this great pioneer's achievements was the foundation of the journal Brain, with Hughlings Jackson, Sir John Bucknill, and Sir James Crichton-Browne.

J M S Pearce

304 Beverley Road, Analby, Hull HU10 7BG, UK; email: imspearce@freenet.co.uk

\section{References}

1 Carpenter W. On the physiological import of Dr Ferrier's experimental investigations into the functions of the brain. West Riding Lunatic Asylum Med Reports 1874;4:1-23.

2 Barfoot M. To ask the suffrages of the patrons: Thomas Laycock and the Edinburgh Chair of Medicine, 1855. Med Hist Suppl 1995; 15:i-xv, 1-226.

3 Pearce JMS. Thomas Laycock (1812-1876) J Neurol, Neurosurg Psychiatry 2002:73:303.

4 Bouillaud JB. Recherches cliniques propres à démontrer que la perte de la parole correspond à la lésion des lobules antérieurs du cerveau, et à confirmer l'opinion de $M$. GALL, sur le siège de l'origine du langage articulé. Arch Gen Med Paris, lére série 1825;8:25-45.

5 Flourens P. Analyse de la philosophie anatomique, ou l'on considère plus particulièrement l'influence qu'aura cet ouvrage sur l'état actuel de la physiologie et de l'Anatomie. Paris: Béchet, 1819.

6 Finger S. Origins of Neuroscience. New York, Oxford University Press, 1994:371-85.

7 Ferrier S. Experimental researches in cerebral physiology and pathology. West Riding Lunatic Asylum Medical Reports 1873;3:30-96. [Translated into French: Paris, Medical Progrés and Delahaye, 1874.]

8 Clarke E, Ferrier D. Dictionary of scientific biography, vol. 4. In C.C. Gillespie, ed. New York, Scribner's, 1971:593-5

9 Fritsch G, Hitzig E. Über die elektrische erregbarkeit des grosshirns. Archiv für Anatomie, Physiologie, und Wissenscahffliche Medicin 1870;300-332.

10 Ferrier $\mathbf{D}$. The functions of the brain, 2 nd ed. London, Smith Elder 1886:268-345.

11 Ferrier D. Functions of the brain. $J$ Physiology, 1892;13:773.

12 Ferrier D. De la localisation des maladies cérébrales, par David Ferrier. Traduit de l'anglais par Henry C. de Varigny. Suivi d'un mmoire sur les localisations motrices dans l'corce des hémisphères du cerveau, par J.M. Charcot et A. Pitres. Paris G Bailliere 1879;8:288.

13 Ferrier $\mathbf{D}$. Les fonctions du cerveau, par David Ferrier. Traduit de l'anglais par Henri C. de Varigny. Paris G Bailliere 1878;8:519.

14 Ferrier D. The Croonian lectures on cerebral localisation. Delivered before the Royal College of Physicians, June 1890. London, Smith Elder, 1890;61:152.

15 Rioch DM. The founders of neurology, 2nd edn. In: Haymaker W, Schiller F, eds. Springfield: Charles C Thomas, 1970:195-8.

16 Sherrington CS. Sir David Ferrier, 1843-1928. Proc Roy Soc 1928;103B(7-16):10-12. 